\title{
Commentary: How Does Oestradiol Influence the AVT/IT System in Female Round Gobies During Different Reproductive Phases?
}

\author{
Hanna Kalamarz-Kubiak
}

Department of Genetics and Marine Biotechnology, Institute of Oceanology, Polish Academy of Sciences, Sopot, Poland

Article Info

\section{Article Notes}

Received: February 10, 2018

Accepted: February 28, 2018

\section{*Correspondence:}

Dr. H. Kalamarz-Kubiak

Department of Genetics and Marine Biotechnology, Institute of Oceanology, Polish Academy of Sciences, Powstańców

Warszawy 55, 81-712 Sopot, Poland;

Telephone: +48 58 7311766, Fax: +48 585512130

Email: hkalamarz@iopan.gda.pl

(c) 2018 Kalamarz-Kubiak H. This article is distributed under the terms of the Creative Commons Attribution 4.0 International License

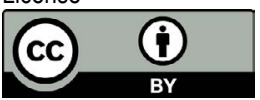

\section{Keywords:}

Oestradiol

AVT/IT system

Fish
Teleostean neuropeptides such as arginine vasotocin (AVT) and isotocin (IT) and their homologues arginine vasopressin (AVP) and oxytocin (OT) are implicated in the regulation of reproduction and social behaviour in vertebrates ${ }^{1,2,3}$. In fish, those neurohormones have also been reported to influence sexual behaviour, including aggression ${ }^{4,5,6}$, courtship ${ }^{7,8,9}$, vocalization ${ }^{10}$, and spawning reflex ${ }^{11}$. In higher vertebrates, AVP/OT systems affect social behaviour by acting within a complex neuronal network defined as a 'social behavioural neuronal network' $(\text { SBNN })^{12,13}$. The SBNN is composed of groups of neurons, defined as nodes that are reciprocally connected, express gonadal steroid receptors, and constitute an important site of regulation or activation of multiple forms of social behaviour ${ }^{14}$. Furthermore, there is evidence that SBNN also exists in non-mammalian vertebrates, including fish ${ }^{15}$.

Oestrogens, synthesized in ovaries or locally in the brain, play well-recognized roles in the neuroendocrine control of reproductive physiology, secondary sex characteristics, and sexual behaviour across vertebrate females ${ }^{16,17}$. In female Lythrypnus dalli, it was presented that the gonadal $17 \beta$-oestradiol $\left(\mathrm{E}_{2}\right)$ concentration was approximately 10 times higher than that in the brain ${ }^{18}$. In higher vertebrates and fish, there are indications of possible interactions between oestrogens and AVP/AVT- and OT/IT-ergic systems. However, studies were focused on the location of these hormones or their receptors in the brain and oestrogen replacement therapy after ovariectomy. So far, to the authors' knowledge, nobody has attempted to check if there is a functional relationship between oestradiol and AVT and IT in fish. Our study presents, for the first time, a presumable mechanism for oestradiol action on the AVT/IT system in female round goby (Neogobius melanostomus) during the spawning-capable phase and the regressing phase. We aimed to determine whether there is a functional relationship between circulating oestradiol and AVT and IT and to establish which pathway, genomic or non-genomic, is involved in this mechanism in different reproductive phases. For this purpose, the brain explants of female round goby were perfused in medium supplemented with $E_{2}$ at doses mimicking the plasma levels of this hormone in nature during different phases of the reproductive cycle. In the perfusion of brain explants, we used $\mathrm{E}_{2}$ separately or in combination with Fulvestrant (ICI 182.780) - oestrogen receptors (ERs) antagonist or Actinomycin D (Act D)-transcription inhibitor.

How does oestradiol influence AVT and IT secretion and what pathway, genomic or non-genomic, is involved in this regulation?

Changes in oestradiol level and other hormones related to the phases 
of the reproductive cycle or social interactions can affect AVP and OT levels by their ERs, which in turn could alter the social behaviour of the individual ${ }^{19,13}$. Most of the research that has focused on the effect of oestradiol on the synthesis and secretion of nonapeptides has been performed in rodents. Usually, AVP and OT levels or mRNA were reduced following ovariectomy and restored with oestradiol replacement ${ }^{20,21}$. In contrast to higher vertebrates, in fish, available information is related only to seasonal changes in gene expression and immunoreactivity of the nonapeptides, which are probably linked with changes in steroids ${ }^{22,23,24}$. Therefore, we presumed that there is a functional link between oestradiol and the AVT/IT system during different phases of the reproductive cycle based on our studies in stickleback ${ }^{25,6,9}$, round goby ${ }^{26}$, and black molly (Poecilia sphenops) ${ }^{27}$.

The results of our study show that during the spawningcapable phase, oestradiol most probably stimulates the release of AVT through classical ERs via both genomic and non-genomic pathways, while IT release is mediated through classical nuclear ERs via a genomic pathway only. In fish and higher vertebrates, the cross-talk between the nongenomic and genomic pathways of oestradiol signalling may also be involved in the control and synchronized maturation and ovulation at the hypothalamic and ovary level ${ }^{28,29,30}$. Our results also suggest that in the regressing phase, the release of both nonapeptides is mediated through classical nuclear ERs via a genomic pathway. It should be mentioned that the mechanism presented here does not exclude the possibility of oestradiol action on the AVT/IT system via non-classical mERs, such as ER-X, GPER, and Gq-mER.

\section{The old new story: from fish to humans}

Various species of aquatic fish and invertebrates have long provided valuable models for the study of basic biological processes. Fish are also useful for pathological and toxicological studies because of the high fecundity and relatively brief generation times. Nowadays, the zebrafish (Danio rerio) is a versatile and robust model organism for the study of vertebrate biology, physiology, and human disease, suitable for both developmental and genetic analysis. Therefore, the zebrafish may bridge the gap between its vertebrate and invertebrate counterparts in genetics and developmental studies. Striking homologies have been found between the reproductive system of humans and zebrafish and many similarities from gene functions to reproductive physiology ${ }^{31}$. Hence, fish may be a perfect model for studying the mechanisms whereby hormones modulate the sexual behaviours in both nonhuman vertebrates and humans. This group of vertebrates demonstrates an exceptional diversity of mating systems and reproductive behaviours. What is more, many fish species present a remarkable plasticity in their biology of reproduction, e.g. sex change, diversity of reproductive tactics that seems to be mediated by the hormone. Furthermore, because the fish neuroendocrine system is well conserved among vertebrates, the mechanisms of hormonal control of behaviour may show similarities with those of other vertebrates ${ }^{32,31}$.

This kind of study requires a special method that allows monitoring the dynamic hormone secretion and registering even small and short-term fluctuations in their release. It should be noted that only the perfusion culture method allows detailed examination of changes in the release of hormones while ensuring optimal culture conditions. So far, organ perfusion methods have not often been used in fish for lack of suitable techniques. However, an innovative system for organ perfusion proposed by Minuth in the early 1990s gives more options for this kind of technique. In our study, we used the procedure for the gradient perfusion technique (3D) developed by Kalamarz-Kubiak et al. ${ }^{33}$, who for the first time applied the MINUCELLS and MINUTISSUE tissue engineering technique for perfusion of fish brain tissues. In this study, brain explants were placed on the membrane between rings of tissue carriers inside the gradient container. A specific construction of this container facilitated the uniform supply of medium to the luminal and basal sides to avoid the dead space. It should be noted that although the procedure has been elaborated for studies of AVT and IT in fish explants, after only minor modification, if any, it can serve many other purposes.

\section{Acknowledgement}

This study was supported by the National Science Centre (Narodowe Centrum Nauki) [2012/05/B/NZ9/01024 to H.K.-K.].

\section{Competing interests}

The authors declare no competing or financial interests.

\section{References}

1. Moore FL. Evolutionary precedents for behavioral actions of oxytocin and vasopressin. Ann N Y Acad Sci. 1992; 652: 156-165.

2. Goodson JL. Territorial aggression and dawn song are modulated by septal vasotocin and vasoactive intestinal polypeptide in male field sparrows (Spizella pusilla). Horm Behav. 1998; 34: 67-77.

3. Goodson JL, Bass AH. Social behavior functions and related anatomical characteristics of vasotocin/ vasopressin systems in vertebrates. Brain Res Rev. 2001; 35: 246-265.

4. Semsar K, Kandel FLM, Godwin J. Manipulations of the AVT system Shift social status and related courtship and aggressive behavior in the bluehead wrasse. Horm Behav. 2001; 40: 21-31.

5. Greenwood AK, Wark AR, Fernald RD, et al. Expression of arginine vasotocin in distinct preoptic regions is associated with dominant and subordinate behaviour in an African cichlid fish. Proc Biol Soc 2008; 275: 2393-2402.

6. Kleszczyńska A, Sokołowska E, Kulczykowska E. Variation in brain arginine vasotocin (AVT) and isotocin (IT) levels with reproductive stage and social status in males of threespined stickleback (Gasterosteus aculeatus). Gen Com Endocrinol. 2012; 175: 290-296. 
7. Salek SJ, Sullivan CV, Godwin J. Arginine vasotocin effects on courtship behavior in male white perch (Morone americana). Behav. Brain Res. 2002; 133: 177-183.

8. Grober MS, Bass AH. Life history, neuroendocrinology, and behavior in fish. In: Hormones, Brain and Behavior. New York: Academic Press. 2002.

9. Kulczykowska E, Kleszczynska A. Brain arginine vasotocin and isotocin in breeding female three-spined sticklebacks (Gasterosteus aculeatus): the presence of male and egg deposition. Gen Comp Endocrinol. 2014; 204: 8-12.

10. Goodson JL, Bass AH. Vasotocin innervation and modulation of vocalacoustic circuitry in the teleost Porichthys notatus. J Comp Neurol. 2000; 422: 363-379.

11. Knapp R, Wingfield JC, Bass AH. Steroid hormones and paternal care in the plainfin midshipman fish (Porichthys notatus). Horm Behav. 1999; 35: 81-89.

12. Newman SW. The medial extended amygdala in male reproductive behavior. A node in the mammalian social behavior network. Ann N Y Acad Sci. 1999; 877: 242-257.

13. Albers HE. Species, sex and individual differences in the vasotocin/ vasopressin system: relationship to neurochemical signaling in the social behavior neural network. Front Neuroendocrinol. 2015; 36: 49-71.

14. Caldwell HK. Oxytocin and Vasopressin: Powerful Regulators of Social Behavior. Neuroscientist. 2017; 23: 517-528.

15. Goodson JL. The vertebrate social behavior network: evolutionary themes and variations. Horm Behav. 2005; 48: 11-22.

16. Knobil E, Neill JD. Female reproduction system. In: The Physiology of Reproduction. New York: Raven Pres. 1994.

17. Nagahama Y, Yoshikuni M, Yamashita M, et al. Regulation of oocyte growth and maturation in fish. Curr Top Dev Biol. 1995; 30: 103-145.

18. Lorenzi V, Earley RL, Grober MS. Differential responses of brain gonad and muscle steroid levels to changes in social status and sex in a sequential and bidirectional hermaphroditic fish. PLoS One. 2012; 7: e51158.

19. Kramer KM, Yamamoto Y, Hoffman GE, et al. Estrogen receptor alpha and vasopressin in the paraventricular nucleus of the hypothalamus in Peromyscus. Brain Res. 2005; 1032: 154-161.

20. Skowsky WR, Swan L, Smith P. Effects of sex steroid hormones on arginine vasopressin in intact and castrated male and female rats. Endocrinology. 1979; 104: 105-108.
21. Bale TL, Dorsa DM. Sex differences in and effects of estrogen on oxytocin receptor messenger ribonucleic acid expression in the ventromedial hypothalamus. Endocrinology. 1995; 136: 27-32.

22. Ota $\mathrm{Y}$, Ando $\mathrm{H}$, Ueda $\mathrm{H}$, et al. Seasonal changes in expression of neurohypophysial hormone genes in the preoptic nucleus of immature female masu salmon. Gen Comp Endocrinol. 1999; 116: 31-39.

23. Ohya T, Hayashi S. Vasotocin/isotocin-immunoreactive neurons in the medaka fish brain are sexually dimorphic and their numbers decrease after spawning in the female. Zool Sci. 2006; 23: 23-29.

24. Maruska KP, Mizobe MH, Tricas TC. Sex and seasonal covariation of arginine vasotocin (AVT) and gonadotropin-releasing hormone (GnRH) neurons in the brain of the halfspotted goby. Comp Biochem Physiol A. 2007; 147: 129-144.

25. Gozdowska M, Kleszczyńska A, Sokołowska E, et al. Arginine vasotocin (AVT) and isotocin (IT) in fish brain: diurnal and seasonal variations. Comp Biochem Physiol B. 2006; 143: 330-334.

26. Sokołowska E, Kleszczyńska A, Nietrzeba M, et al. Annual changes in brain concentration of arginine vasotocin and isotocin correspond with phases of reproductive cycle in round goby, Neogobius melanostomus. Chronobiol Int. 2015; 32: 917-924.

27. Kulczykowska E, Kalamarz-Kubiak H, Nietrzeba M, et al. Brain nonapeptide and gonadal steroid responses to deprivation of heterosexual contact in the black molly. Biology Open. 2015; 4: 69-78.

28. Vasudevan N, Pfaff DW. Non-genomic actions of estrogens and their interaction with genomic actions in the brain. Front Neuroendocrinol. 2008; 29: 238-257.

29. Roepke TA, Qiu J, Bosch MA, et al. Cross-talk between membraneinitiated and nuclear-initiated oestrogen signaling in the hypothalamus. J Neuroendocrinol. 2009; 21: 263-270.

30. Thomas P. Role of G-protein-coupled estrogen receptor (GPER/ GPR30) in maintenance of meiotic arrest in fish oocytes. J Steroid Biochem Mol Biol. 2017; 167: 153-161.

31. Hoo JY, Kumari Y, Shaikh MF, et al. Zebrafish: A Versatile Animal Model for Fertility Research. Bio. Med. Research International. 2016; 9732780 .

32. Gonçalves D, Oliveira R. Hormones and Sexual Behavior of Teleost Fishes. In: Hormones and Reproduction of Vertebrates. Elsevier Inc. 2010.

33. Kalamarz-Kubiak H, Gozdowska M, Nietrzeba $M$, et al. A novel approach to AVT and IT studies in fish brain and pituitary: In vitro perfusion technique. J Neurosci Methods. 2011; 199: 56-61. 